\title{
TITLE:
}

\section{DIFFERENTIATION AND SYMBIOSIS IN TWO HYDROZOANS}

$\operatorname{AUTHOR}(\mathrm{S})$ :

Hirai, Eturo; Kakinuma, Yoshiko

CITATION:

Hirai, Eturo ...[et al]. DIFFERENTIATION AND SYMBIOSIS IN TWO HYDROZOANS. PUBLICATIONS OF THE SETO MARINE BIOLOGICAL LABORATORY 1973, 20: 257-273

\section{ISSUE DATE:}

1973-12-19

URL:

http://hdl.handle.net/2433/175774

RIGHT: 


\title{
DIFFERENTIATION AND SYMBIOSIS IN TWO HYDROZOANS ${ }^{1 \text { ) }}$
}

\author{
ETURô HIRAI and YosHIKo KAKINUMA \\ Marine Biological Station, Tôhoku University, Asamushi, Aomori City
}

With 15 Text-figures

\section{Introduction}

We have been investigating coelenterate life cycles and organ differentiation, especially in certain hydrozoans and scyphozoans. At the beginning of the laboratory observation of the developmental cycle in those species, some experiments are necessary to find out the suitable substrata for polyps and planulae. Those of some species easily attach themselves to the wall of petri dish and develop there into a colony; but in some other species they need some physical stimuli; still in other species is needed some very simple chemical substance, iodine $\left(\mathrm{I}_{2}\right)$ or carbon dioxide $\left(\mathrm{CO}_{2}\right)$ for example.

Many hydroids are associated with such molluscs as gastropods, bivalves and scaphopods, as well as animals of other phyla. Colonies of the hydrozoan Cytaeis uchidae are found associated with and attached to the shell surface of the gastropod Niotha livescens, and another hydrozoan, Proboscidactyla sp., live commensally on the tube of the polychaete, Pseudopotamilla occelata. However, no explanation has been made to account for these specific obligatory associations.

The purpose of our research was to investigate the mechanisms underlying the differentiation of organs and the symbiotic relation between the hydrozoan and its host.

\section{Materials and Methods}

The gastropod Niotha livescens, each with a colony of the hydrozoan Cytaeis uchidae, live on the sandy shore at Ôra near Asamushi. The molluscs were collected by attracting them by fish pieces scattered on the shallow sandy shore. The observations of the life cycle of the animals were carried out in the field and also on materials which were placed in the laboratory on a sandy bed in a glass aquarium with circulating sea water. $N$. livescens were fed with fish and $C$. uchidae with brine shrimp. The polychaete, Pseudopotamilla occelata, with a colony of the hydrozoan Proboscidactyla sp. attached to its tube, live on the rocks in shallow coastal waters in the neighbourfood of the Asamushi Marine Biological Station. The materials used in this study were collected together with a small part of the substrative rocks from the shore just near

1) Contributions from the Marine Biological Station, Tôhoku University, Aomori City, No. 406. 


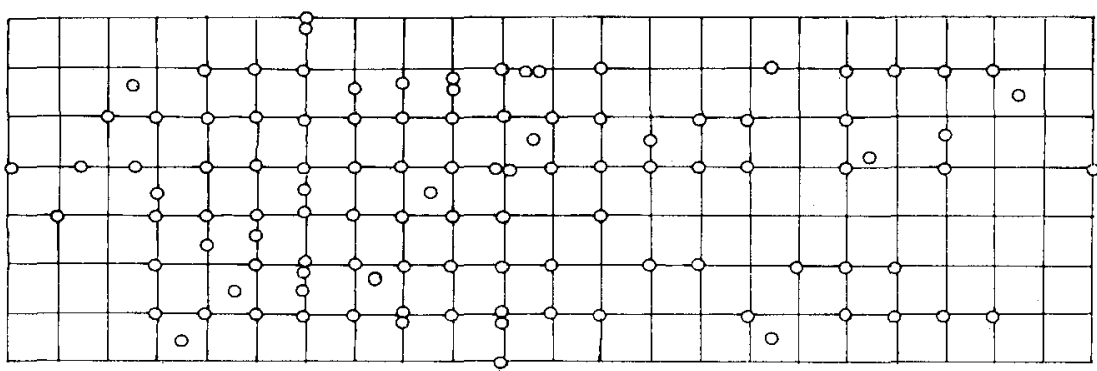

Fig. 1. A normal pattern of the colony of Cytaeis uchidae on the shell surface of Niotha livescens; Lines represent the stolons and circles the polyps. Stolons run mostly along the grooves on the shell.

the station or at Tsuchiya not so far from the station. In the laboratory, the materials of Pr. sp. and Ps. occelata were kept in running sea water for observations of the life cycle. The animals experimented with were reared at $20^{\circ} \mathrm{C}$, the water being changed every day. Both Pr. sp. and Ps. occelata could be maintained on a mash of brine shrimp larvae and fish.

\section{Results of Experiments and Observations}

\section{Cytaeis uchidae}

\section{Life Cycle in the Field and Developmental Cycle in the Laboratory:}

The colony of the hydrozoan $C$. uchidae was found associated with and attached to the shell surface of the gastropod Niotha livescens. The stolon of $C$. uchidae was observed creeping in the fine reticulate grooves of the mollusc, and most of the polyps appeared at the intersection of the transverse and longitudinal grooves (Fig. 1). N. livescens are found creeping around on the sandy floor on clear days when the sea is calm from the end of May to early September, when the water temperature is higher than $17^{\circ} \mathrm{C}$. In spring and autumn, while the temperature of the sea water is above $10^{\circ} \mathrm{C}$, they may come out of the sand being attracted by fish pieces scattered in their habitat. In winter, however, when the water temperature drops to about $10^{\circ} \mathrm{C}$ or below, the animals have never been seen, even if fish pieces were scattered in their habitat. Probably these animals have a vertical migration according to the seasons.

We have not seen the process of growth of the hydrozoan colonies which we collected in the field. According to field observations, from spring to autumn, the colonies covered the whole shell surface, and medusa formation occurred only in summer. Especially abundant medusa buds appeared from the end of June to the beginning of August. On the other hand, we have not yet found any specimens of $N$. livescens without a colony of $C$. uchidae. The breeding of $N$. livescens occurred at the same season as medusa formation.

In the laboratory, many $N$. livescens reared in a glass aquarium could be ob- 
served migrating through about $10 \mathrm{~cm}$ of sand layer to the bottom in winter. In spring, as the temperature rose by $10^{\circ}$ to $15^{\circ} \mathrm{C}$, the $N$. livescens came up on the surface of the sand. At this time we found that the mollusc shed off the colony, leaving the shell neat and clean. However, this is quite different from what can be observed in nature.

In the laboratory, polyps sometimes appeared on an irregular part of the stolon in a colony which had been kept for a long time and fed with brine shrimp. The medusae grew to full size and were liberated from the stolon in about ten days after the buds appeared, at $20^{\circ} \mathrm{C}$. The young medusae immediately after release are $0,5 \mathrm{~mm}$ in diameter, and have four radial canals and four tentacles. The young medusa becomes an adult within 7 days after liberation, and is about $0,7 \mathrm{~mm}$ to $1 \mathrm{~mm}$ in diameter. This medusa maintains the same structure throughout its development. We hoped to observe the attachment of the planula of $C$. uchidae to the shell surface of a young $N$. livescens, but the cultured adult medusae were all females, and thus this was not realized. Egg masses of $N$. livescens were observed in the laboratory on the 19th of July, 1968 and the 3rd of August, 1970. The development of the young molluscs could be traced during one year until they attained about 5 to $7 \mathrm{~mm}$ in body length.

Transplantation of Polyps of Cytaeis uchidae to Several Kinds of Structure:

(1) Polyps transplanted to a glass surface

Polyps were isolated from colonies of $C$. uchidae and transplanted to the glass bottom of petri dishes. After one or two days, the polyps attached to the glass surface, and sufficient food of brine shrimp was provided for them, but the stolons did not increase normally. The colonies expanded to only two or three polyps, even though many medusa buds appeared on them, and then disappeared within one or two months.

(2) Polyps transplanted to a vinyl chloride plate with reticulate engraving

Counterfeits of the reticulate shell grooves were sculptured on the surface of vinyl chloride plates. In two or three days, polyps transplanted on such plates attached to the plate structure and formed small colonies with medusa buds. The stolons elongated regularly or irregularly along the sculptured grooves. But then, the colonies began to decrease in size, and disappeared after about a month.

(3) Polyps transplanted to the old empty shell of Mytilus

Polyps were transplanted to the external and internal surfaces of the shell of Mytilus edulis. In one or two days, the polyps settled on both surfaces. Small colonies were formed, but they moved to the periphery of the shell. Up to three medusa buds appeared, then the colonies disappeared within half a month.

(4) Polyps transplanted to the old empty shell of Niotha

Polyps were transplanted to the shells of $N$. livescens which had been kept dried for more than two years and immersed in sea water for four days before transplantation. The results were somewhat similar to those in the case of transplantation to the shell of Mytilus. The colonies expanded but soon degenerated, the stolon was irregular as compared with the normal feature and did not always elongate along the grooves. 
No active formation of medusa buds was observed.

(5) Polyps transplanted to the fresh shell of $N$. livescens without the soft body

Polyps were transplanted to the shell surface of $N$. livescens from which the soft body had just been removed; the shells were brushed to remove the colonies of $C$. uchidae and cleaned by immersing them in fresh water for two days. In one or two days, the polyps attached to the shell surface, the stolon elongated along the grooves, and the colony expanded to some extent, but clearly less than in next experiment. These colonies survived more than three months (Fig. 2).

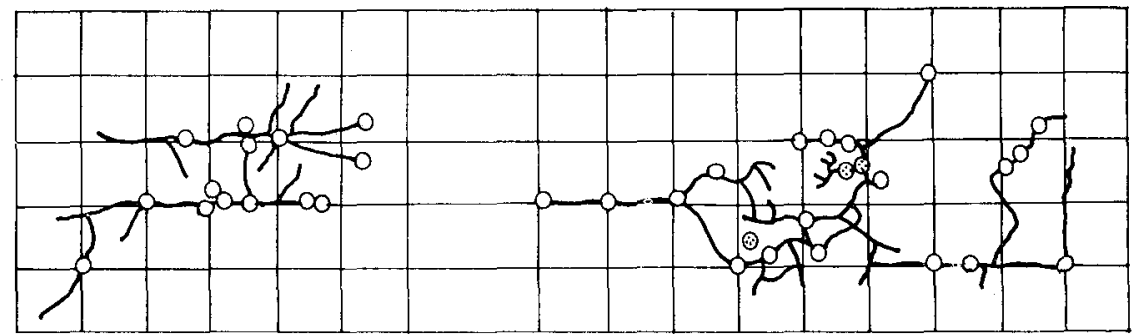

Fig. 2. Cytaeis uchidae, diagram of two colonies from the polyps transplanted on the shell of $N$. livescens from which the soft body was removed. After three weeks.

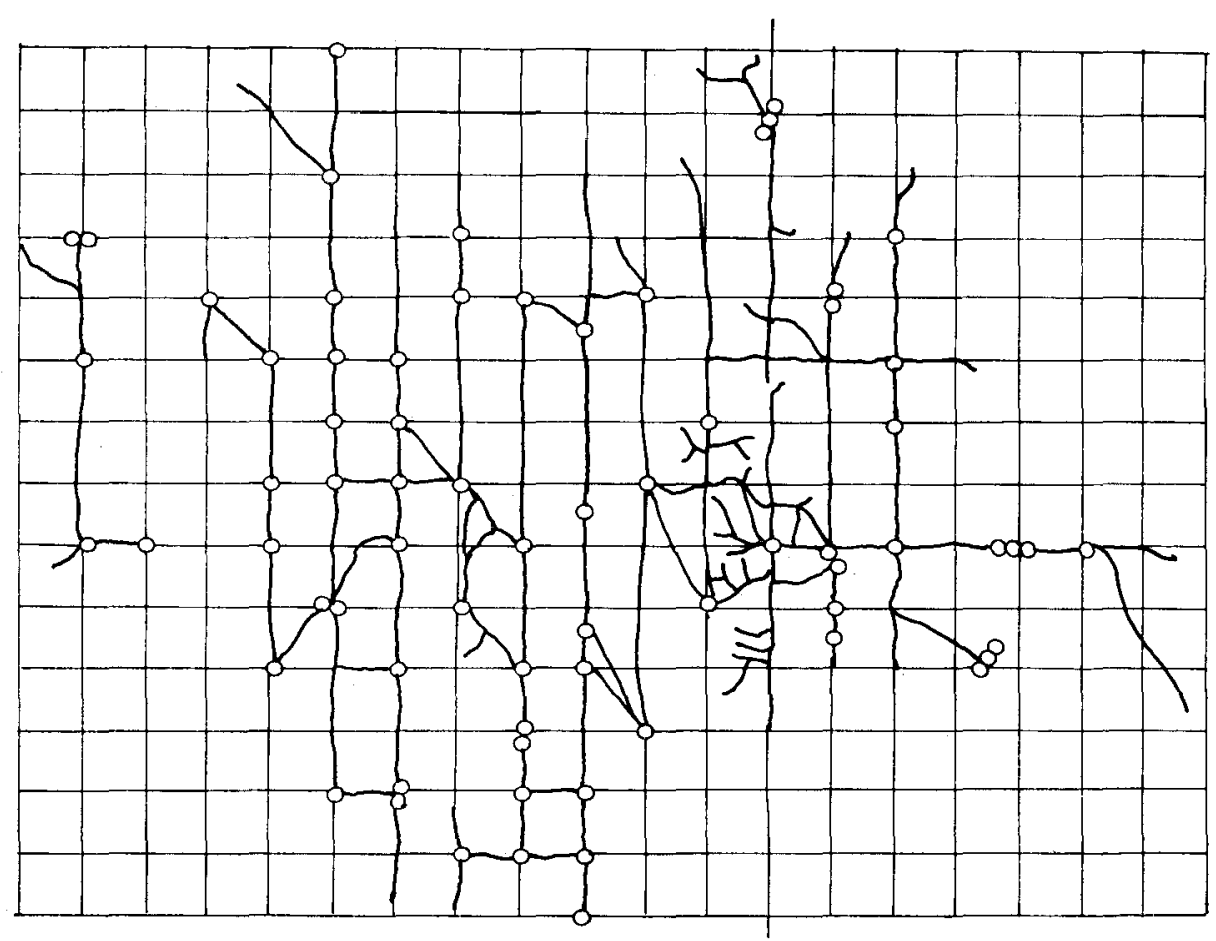

Fig. 3. Cytaeis uchidae, diagram of a part of the colony developed from the polyps transplanted on the shell of living $N$. livescens. After three weeks. 
(6) Polyps transplanted to the shell of living $N$. livescens

Polyps transplanted to living shells of $N$. livescens, settled on the shell surface within a day, the stolon elongated along the grooves and most of the polyp buds were formed regularly at intersections of the grooves. The colony expanded markedly along the grooves over the whole shell surface until a normal colony was completed (Fig. 3).

Table 1. Results of the experiments with several kinds of substrata in Cytaeis uchidae. When the colony was in a normal state and well fed, the polyps developed to a great number, the stolons were normal, and the medusa buds were formed also normally; without food, the polyps became less numerous. When the colony was separated from the host shell but well fed, the polyps became less numerous, the stolons were the same, but the medusa buds increased remarkably; without food, no polyps remained, the stolons degenerated, and no medusa appeared. When the transplantation of polyps was made to the glass wall of a petri dish, a few polyps were issued but they degenerated as well as the stolons, while more medusa buds developed on stolons. When the transplantation was made to the vinyl plate, the shell of Mytilus, or the old empty shell of Niotha, the polyps and stolons degenerated and no medusa bud appeared. When polyps were transplanted to the fresh empty shell of Niotha, only a few polyps appeared and stolons appeared, too, but irregularly, while numerous medusa buds developed on stolons. The transplantation to the shell of living Niotha brought colonies in a quite normal state.

\begin{tabular}{|c|c|c|c|c|}
\hline \multicolumn{2}{|c|}{ Colony } & $\begin{array}{l}\text { Polyps } \\
\text { (colony } \\
\text { formation) }\end{array}$ & \multirow{2}{*}{$\begin{array}{c}\text { Stolons } \\
\text { (intersection) } \\
+\end{array}$} & Medusa buds \\
\hline \multirow{2}{*}{ In natural state } & with food & $++t$ & & + \\
\hline & without food & ++ & + & + \\
\hline \multirow{2}{*}{$\begin{array}{l}\text { Separated from } \\
\text { the host shell }\end{array}$} & with food & + & + & ++ \\
\hline & without food & - & $(+)$ & - \\
\hline \multirow{6}{*}{$\begin{array}{c}\text { Polyp } \\
\text { transplanted } \\
\text { to }\end{array}$} & the petri-dish & $+\rightarrow-$ & & +++ \\
\hline & the vinyl plate & $+\rightarrow-$ & +- & - \\
\hline & $\begin{array}{l}\text { the empty shell of } \\
\text { Mytilus }\end{array}$ & $+\rightarrow-$ & & 一 \\
\hline & $\begin{array}{l}\text { the old empty shell of } \\
\text { Niotha }\end{array}$ & $+\rightarrow-$ & +- & - \\
\hline & $\begin{array}{l}\text { the fresh shell of Niotha, } \\
\text { soft body extracted }\end{array}$ & + & $+\quad-$ & $+t+$ \\
\hline & $\begin{array}{c}\text { the shell of living } \\
\text { Niotha }\end{array}$ & +++ & + & + \\
\hline
\end{tabular}

Separation of the Normal Colony of $C$. uchidae on the Shell of N. livescens, from the Host's Soft Body:

In order to isolate a colony of $C$. uchidae from the living parts of its host, the soft body of the mollusc may be removed with a scalpel, or the shell may be broken with a hammer, and parts of the colony attached to the fragments may be collected to 


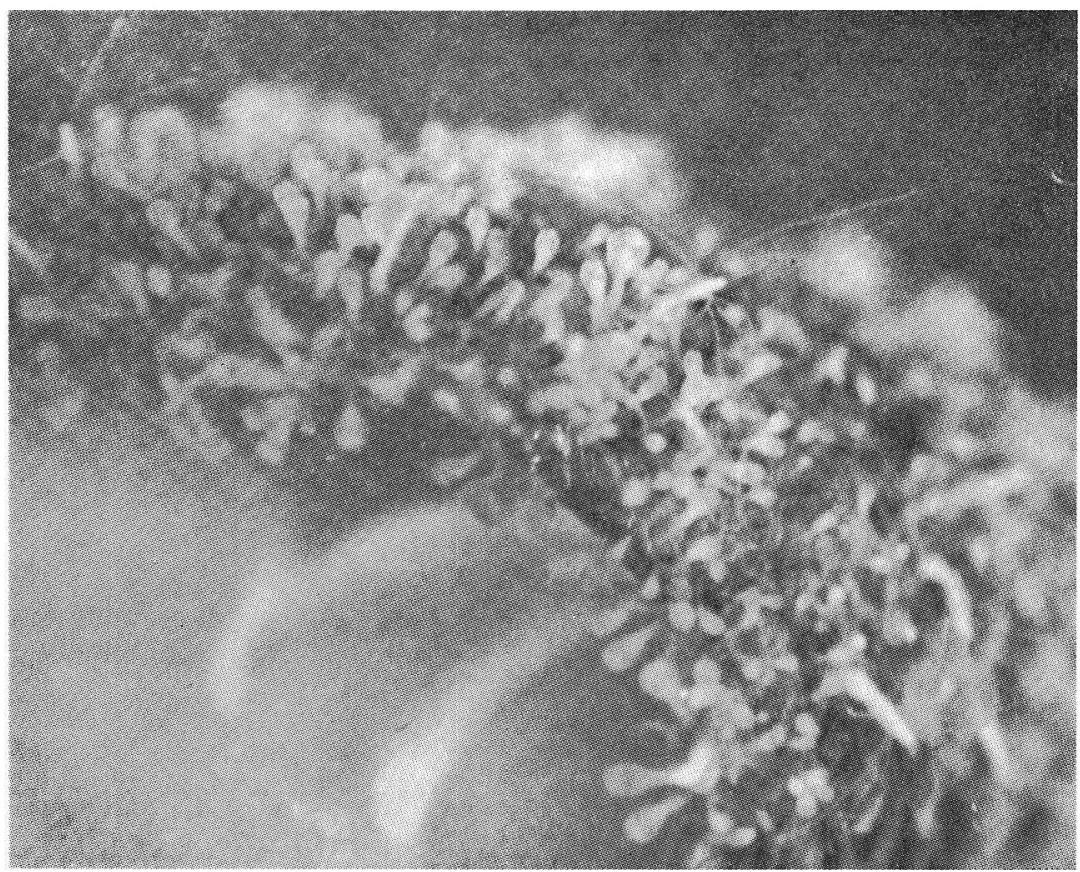

Fig. 4. Cytaeis uchidae, numerous medusa bud on the internal side of the lip of the shell aperture, the soft body is extracted.

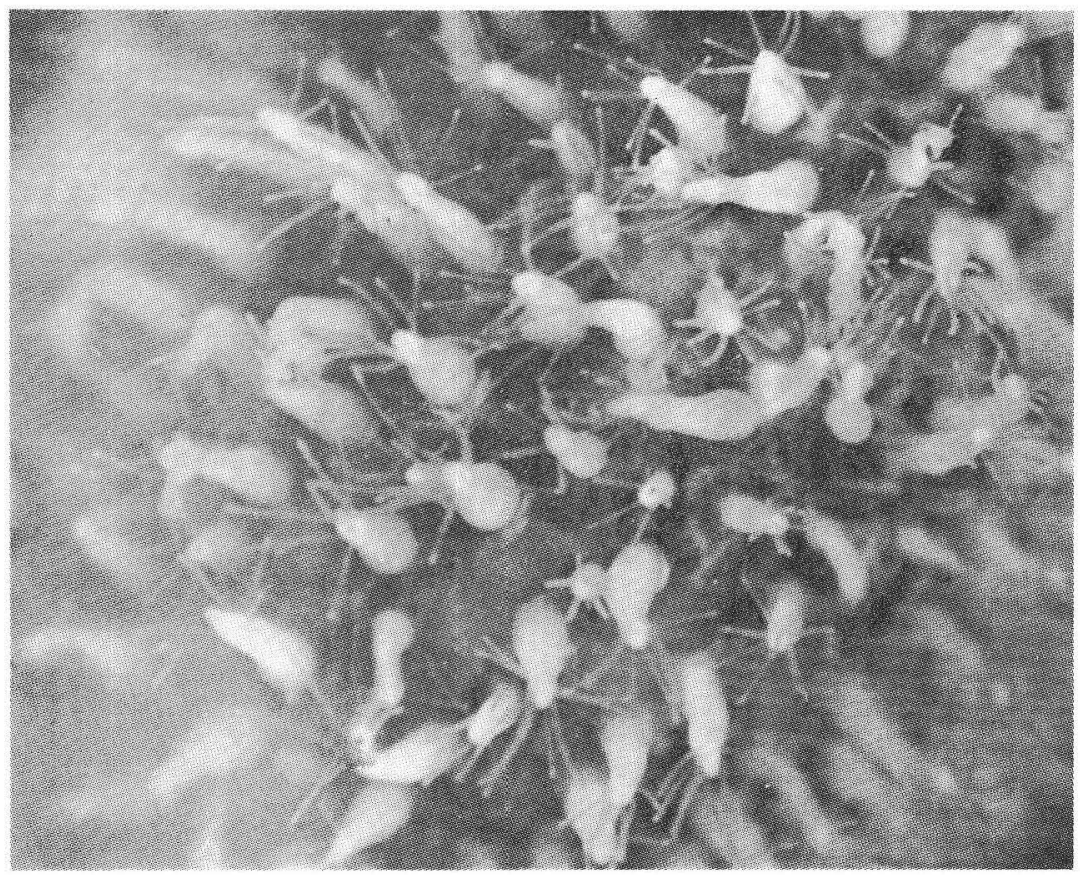

Fig. 5. Cytaeis uchidae, a part of the control colony on an intact mollusc. 


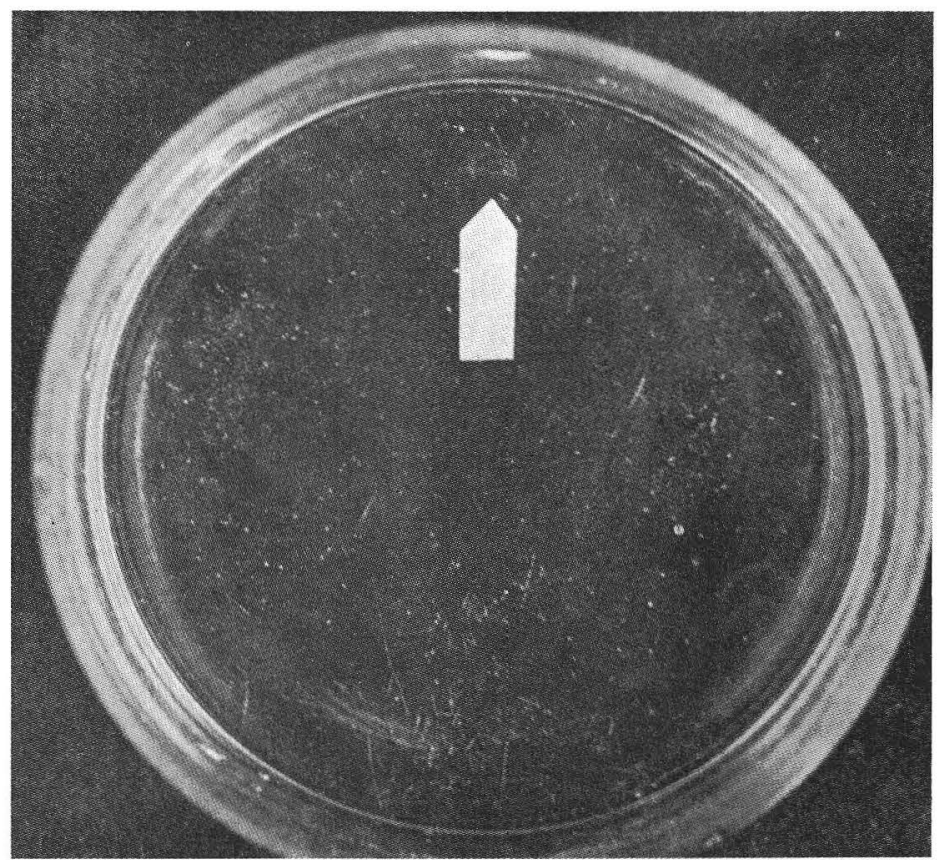

Fig. 6. Cytaeis uchidae, a colony transplanted on the glass, after about 25 days.

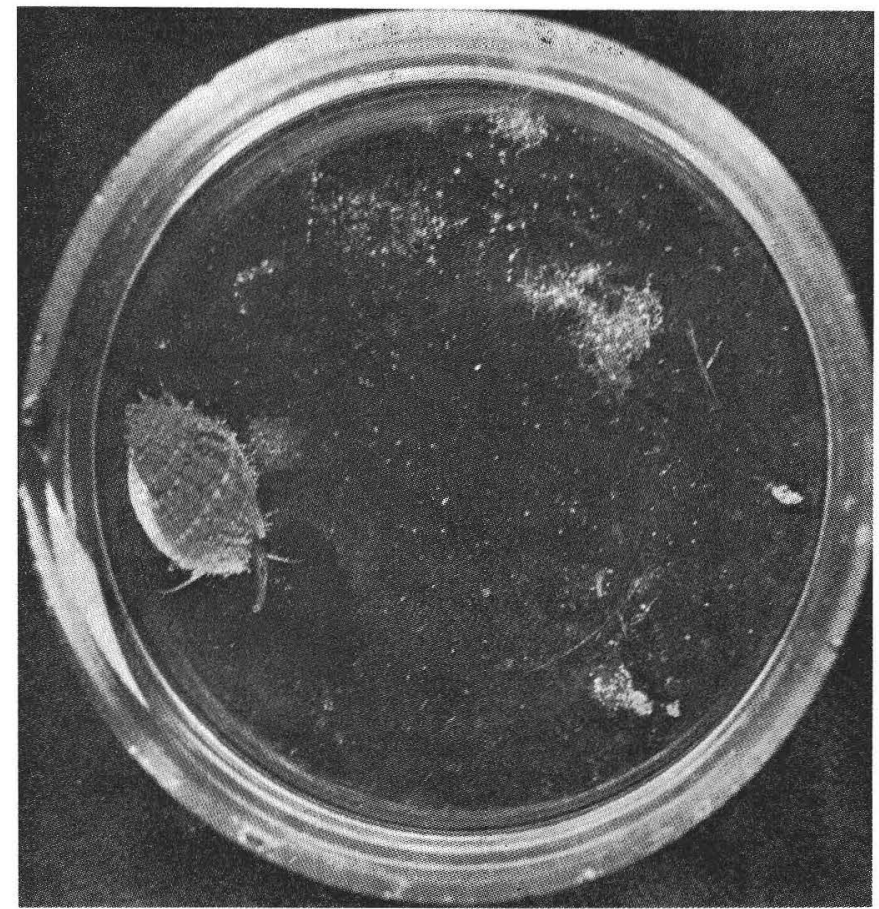

Fig. 7. Cytaeis uchidae, colonies transplanted on the glass, with a creeping gastropod in the same dish, after the same time span. 
be cultured. In the first treatment, after about three weeks numerous medusa buds appeared in the colonies, especially on the internal side of the shell aperture, while the polyps disappeared from the rest of the shell (Fig. 4). On the other hand, only a few medusa buds were produced in the control colonies on intact molluses (Fig. 5). Colony fragments on shell pieces began to degenerate within a week, most of the polyps disappearing, though some of them moved to the internal surface of the shell piece. Amazingly numerous medusa buds (ca. 1000) were differentiated in these colonies, even in the off-season of medusa formation in natural environments. No medusa buds were observed in the control colonies on living $N$. livescens.

In another experiment, colony parts on shell fragments were kept in sea water at about $20^{\circ} \mathrm{C}$, and a living gastropod was introduced into one of the petri dishes. In the control dish without any gastropod, numerous medusa buds appeared in colonies after nine days, but no buds were observed in any colonies cultured together with the creeping gastropod.

Colonies of C. uchidae on Shell Pieces kept with the Gastropod in the Same Dish, but their Direct Contact being Prevented:

C. uchidae on shell pieces of $N$. livescens were cultured at about $20^{\circ} \mathrm{C}$, being kept in one half of a petri dish separated by a screen of Müllergaze from the other half in which a living gastropod was placed. In another petri dish, colony was attached to the glass of the dish in advance, a living gastropod was placed, but being prevented from touching the colony in a similar way. Numerous medusa buds appeared in both of these cases in which the hydrozoan colony and the gastropod were in the same medium.

A further experiment was made to see the formation of medusa buds. Polyps were transplanted to three petri dishes $(a, b, c$,$) and provided with sufficient food.$ The dish a was left in this state, then the colonies expanded a little for about a month, but then degenerated, leaving some empty thecae of stolons (Fig. 6). A living $N$. livescens was placed in each of the petri dishes $\mathrm{b}$ and $\mathrm{c}$ after the attachment of polyps was completed, then colonies developed much better as compared with those in dish a (Fig. 7).

In two months, the colonies expanded irregularly to $2,5 \mathrm{~cm}$ in diameter and to include about 350 polyps, when the gastropod was removed from the petri dish $\mathrm{c}$. After two weeks, many medusa buds appeared on the colony in the dish c, which survived for two more months, but then degenerated.

\section{Proboscidactyla sp.}

Life Cycle in the Field and Developmental Cycle in the Laboratory:

Colonies of $\mathrm{Pr}$. sp. are found around the open end of the nest tube of the polychaete, Pseudopotamilla occelata, throughout the year in the field. Especially large colonies with many polyps are found from spring to autumn. Medusa formation has been observed from about late May to early October. The colony is attached to the end of the tube, with the so-called ventral side of polyps towards the tube hollow 
(Fig. 8). Medusa buds are visible on the middle part of the gonozooid as a ring of

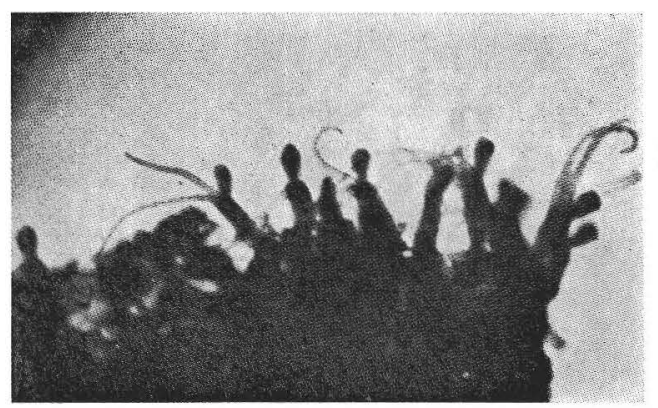

Fig. 8. Proboscidactyla sp., colony is growing around the open end of the nest tube of Pseudopotamilla occelata.

transparent grooves. In the laboratory, the buds develop to medusae ready to be liberated in about ten days at $20^{\circ} \mathrm{C}$. Medusae are formed only on the gonozooids located at the upper part of the worm tube, though gonozooids are distributed all over the rest of the tube. The young medusa with six radial canals, just released from the gonozooid, is $0,5 \mathrm{~mm}$ in height and $0,7 \mathrm{~mm}$ in diameter. The medusa liberated first from the gonozooid has six radial canals, but the canals decrease gradually to five and then to four in successively liberated medusae.

As both Pr. sp. and Ps. occelata can be maintained on mash of fish and brine shrimp larva, we are able to control all stages of these animals in the laboratory throughout the year. The optimum temperature for the asexual reproduction of this hydrozoan is about $20^{\circ} \mathrm{C}$ in the laboratory. A complete colony is needed to secure gonozooids, and gonozooids will revert to dactylozooids whenever the conditions of culture are unfavorable.

We succeeded in obtaining eggs, even in the off-season of natural spawning, from Ps. occelata cultured outside their tubes in petri dishes for a month at 15 to $20^{\circ} \mathrm{C}$. The breeding of both the polychaete and the hydrozoan was observed from May to August in the field. We could observe the development of the polychaete, throughout the larval metamorphosis from the egg to the young adult. The polychaete larva began a sedentary life four days after fertilization.

Experiment with Gastrozooids and Polychaete Tentacles:

At first we thought the differentiation of the gastrozooid might depend on the moving of tentacles of Ps. occelata. The stolon with polyps and moving tentacles of the polychaete were put together into a glass tube, but only one or two more polyps (gastrozooids) were formed on the stolon.

Cutting off the Rim of Worm Tube, furnished with Hydrozoan Colony:

After the tube edge was cut off, the worm kept moving in and out and regenerated a new, thin and transparent tube wall at the cut edge. The stolons on the remaining part of the tube elongated along the tube axis onto the newly built wall, reached the new rim of the tube and finally formed there a complete colony of polyps (Fig. 9). 


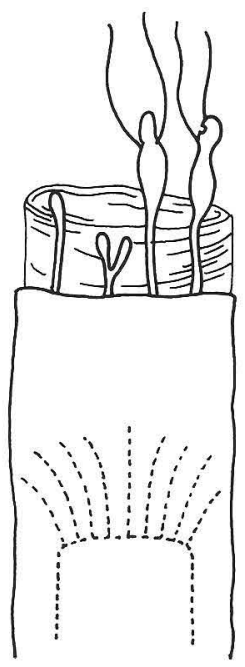

Fig. 9. Proboscidactyla sp., colony formation on the regenerated wall at the cut edge of the worm tube.

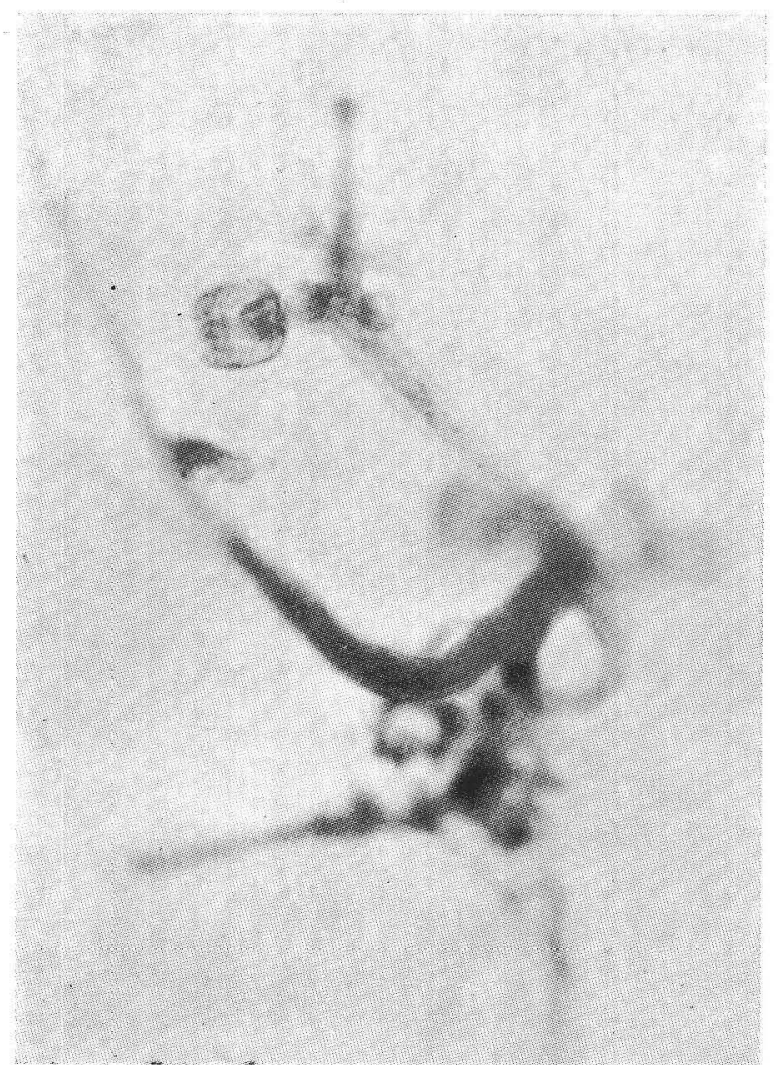

Fig. 10. Proboscidactyla sp., gonozooid arisen from the entangling stolon on the glass bottom.

On the other hand, on the rim of the worm tube cut off and kept isolated, the polyps degenerated to the stolon, this attached to the bottom of the petri dish and elongated, issuing branches overlapping one another, and gonozooids appeared on the top of the entangling stolons at $20^{\circ} \mathrm{C}$ in the laboratory. After three days medusa buds developed one after another on the middle part of respective gonozooids (Fig. 10).

Separation of the Worm from its Colony-bearing Tube:

We kept a worm, removed with a forceps from its nest tube, in a glass tube which was then covered with the worm's empty tube carrying a colony of hydrozoans on it, the nest tube being tied to the glass tube by threads. The polyps on the nest tube degenerated, while the stolons elongated. When the worm in the glass tube began to secrete a new nest, the elongating stolons passed over the edge of the glass tube, and polyps differentiated at the end of the nest tube. Finally the colony of hydrozoa was re-established on the newly formed tube of the worm.

Differentiation of Polyps on Stolons in Direct Contact with Pieces of the Worm Body:

The body of the worm was cut into six parts and placed nearby the hydrozoan 


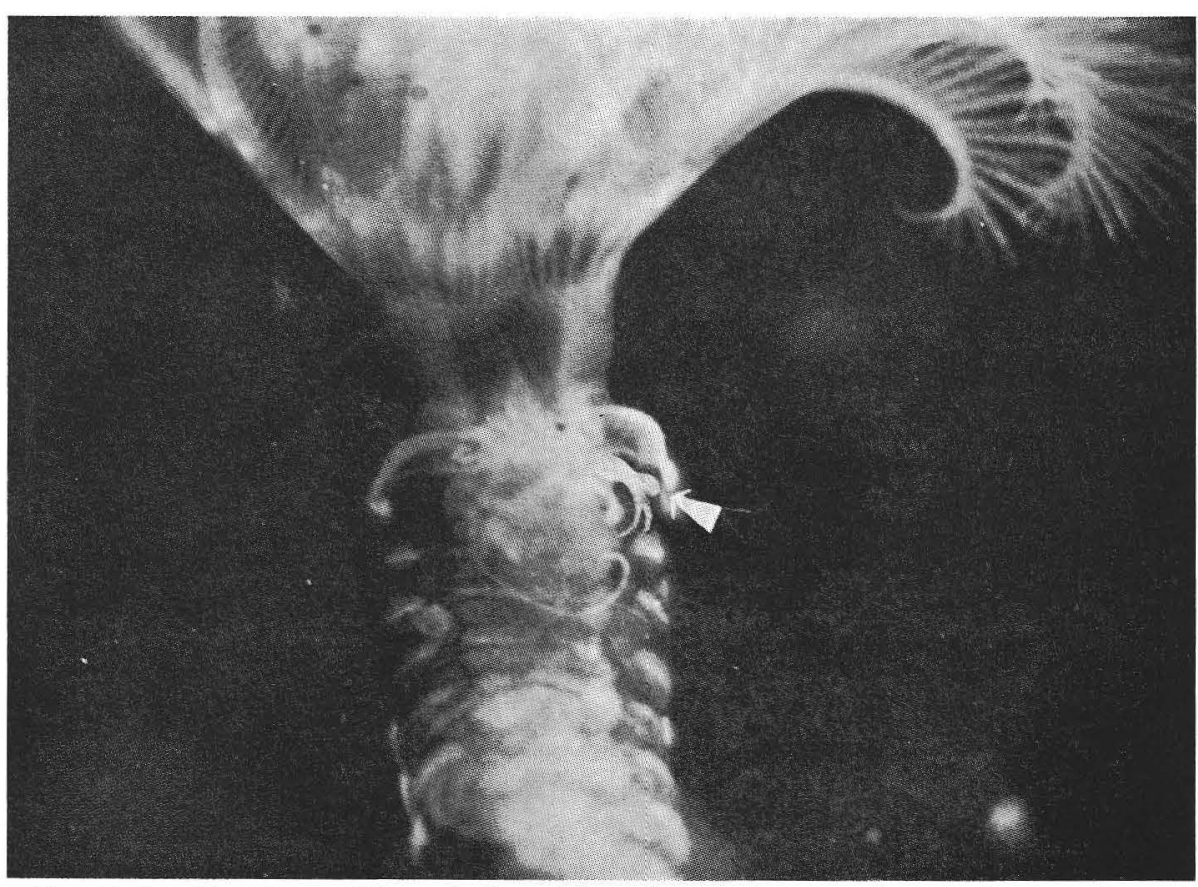

Fig. 11. Proboscidactyla sp., differentiation of the polyp on the mass of secreted mucus formed on the dorsal part of the worm trunk. In this case, the anterior half of the trunk carries tentacles and collar, though the existence of the latter two body parts never showed any special effects. The features of the hydrozoan were the same as in the case of the anterior half of the trunk only.

colony; the first piece comprised tentacles, the second piece the collar, the third and fourth, and fifth and sixth respectively anterior and posterior parts of the trunk and tail. When the cut ends of respective pieces were closed long stolons of the hydrozoan wound around each piece. No essential difference was found between the anterior and posterior parts of the trunk or the tail.

The contact with the stolons kept the isolated tentacular crown in continuous active movement; this gradually caused the stolons to form a spherical mass. There was no differentiation of polyps or other organs on stolons. The collar piece gradually degenerated and no differentiation took place in the stolons clinging to it. Both anterior and posterior pieces of the trunk maintained continuous contraction and extension and secreted the tube-forming mucous substance on their ventral side. The stolons were found elongating and concentrating over the opaque lump of the mucous substance gathered on the dorsal part of the trunk by its movement. The polyps appeared on the periphery of the mucous lump to fit respective joint grooves between the trunk segments (Fig. 11). These gastrozooids were then separated from the worm trunk by elongation of stolons and disappeared. The isolated tail pieces secreted a smaller quantity of tube-forming substance than in the case of the trunk pieces. Although the stolons attached once to this secreted mucous membrane, they 
were soon detached from the tail by very active contractions in this part, and no differentiation occurred on stolons.

Differentiation of Gastrozooids at the Edge of Tubes containing Various Parts of the Worm Body:

The polychaetes were removed from their tubes, cut at various levels, and replaced in tubes carrying polyps after the wounds had healed. When the tube contained a worm body without its tentacles, the polyps remained normal. When the replaced worm lacked both collar and tentacles, about 30 percent of the polyps degenerated. The polyps were reduced with the increase of anterior segments removed from the worm body. When the polychaete was removed from the nest tube, the polyps attached to it degenerated into stolons within about two days. If any parts of the worm body were replaced in such tubes bearing degenerated polyps (stolon), regeneration of polyps occurred to some extent, although less regeneration was observed with the tail part (Fig. 12) and a distinct regeneration was observed only when a whole worm body

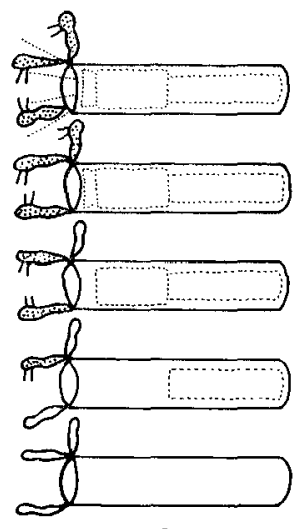

a

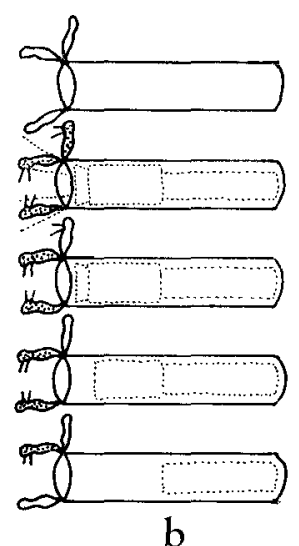

b

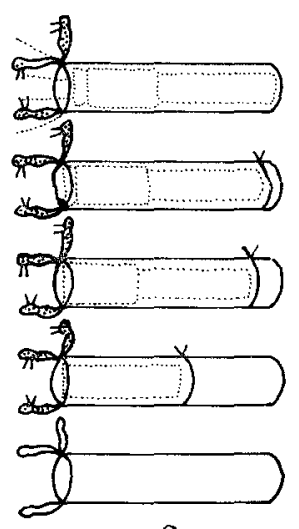

$\mathrm{C}$

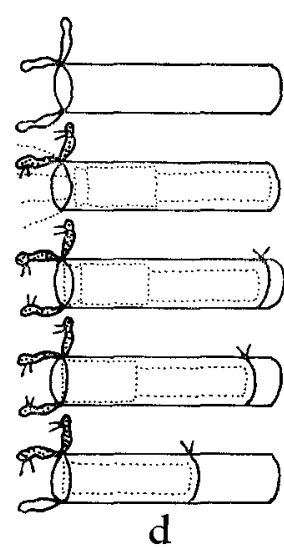

d

Fig. 12. Proboscidactyla sp., differentiation of polyps at the tube edge induced by pieces of the worm body. (a) Pieces of the worm body replaced in the intact tube. Polyps decreased with shortening of body piece replaced. (b) Pieces of the worm body replaced in tubes bearing only stolons. Regenerated polyps increased with elongation of the body piece replaced. (c) Polyps remained normal, when any replaced body piece was kept in contact with the tube opening. (d) Stolons developed to normal polyps when any replaced body piece was kept in contact with the tube opening.

was replaced. These results were obtained when the replaced piece of the worm body was kept apart from the rim of the tube. When the replaced piece of the worm body was kept in close contact with the rim of the tube by constricting the basal part of the tube with thread, regeneration of polyps occurred more extensively.

Differentiation of Polyps from Stolons which adhered to the Tube of Juvenile Pseudopotamilla:

The stolons of Proboscidactyla were placed in a petri dish containing a juvenile of 
Pseudopotamilla, eight days after spawning. In this stage, a thin transparent tube was formed around the juvenile. The stolons elongated in various direction on the dish bottom and when they touched the tube, they elongated towards its opening, and gastrozooids of normal size were differentiated there (Fig. 13). Also, when the stolon directly touched the young polychaete, it differentiated into a gastrozooid within a day, about half the time usually required for the case of contact with an adult polychaete. The juvenile seemed to be burdened with the polyp, but its growth was not disturbed by this. On the other hand, some polyps appeared on the tube at the tail end of the juvenile, but they disappeared within about two days. When polyps were transferred to the tail end of an adult polychaete, the gastrozooids differentiated there were smaller than the normal ones.

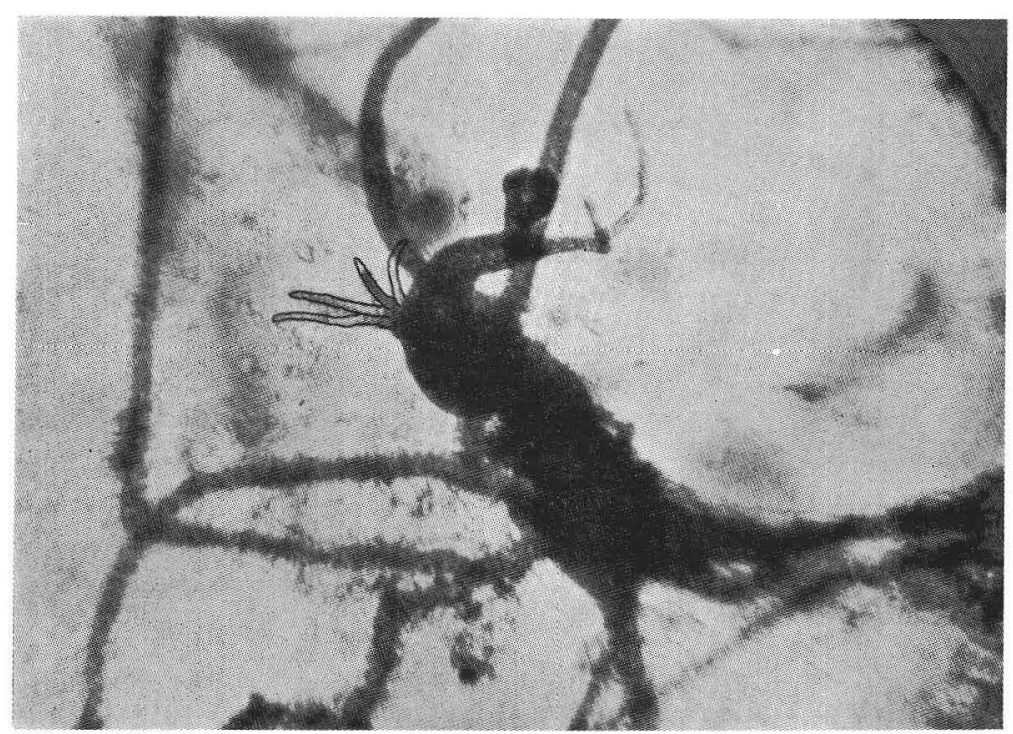

Fig. 13. Proboscidactyla sp., differentiation of the polyp on the tube of a juvenile of Pseudopotamilla occelata.

In another experiment, various growing stages of naked Pseudopotamilla were placed in close contact with a stolon of Proboscidactyla; the polyp differentiated from the stolon creeping in the axis of general stolon elongation. When the naked polychaete did not touch the stolon, no polyp differentiated. When the polychaete became fixed by secreted mucus for tube building, and the elongating stolons touched the newly built tube, the latter differentiated into polyps at the open end of the tube. Polyps formed on a free stolon disappeared after two days. When the temperature was lowered by about $5^{\circ} \mathrm{C}$ after polyp formation in these observations, the stolon elongation was suppressed till it stopped, though the polyps survived more than a week. 
Re-establishment of a Colony of Proboscidactyla:

A square patch was removed from the edge of a worm tube carrying a colony of Proboscidatyla so that the tentacle base of the worm could be seen through this incision. It was found that the tentacles did not protrude to the level of the tube edge. As the worm secreted a new material to form a thin transparent wall to repair the incision, parts of the stolon elongated on to it in club-shaped stolons. These increased in number and elongated along the tube axis, and their tip differentiated into a gastrozooid. When the newly secreted membrane extended about half as long as the original wall, the worm stopped further secretion, and the colony of polyps restored completely

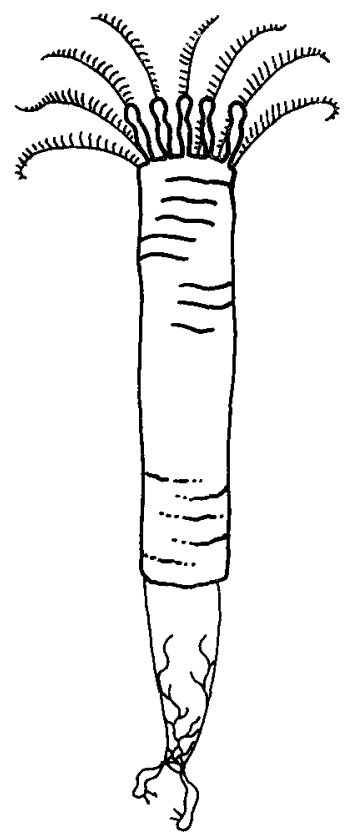

Fig. 14. Proboscidactyla sp., differentiation of polyps at the tail end of the tube. its circular arrangement.

Differentiation of Polyps from the Tail End of the Tube:

The tail end of the tube of Pseudopotamilla was cut off and the worm in the rest of tube was placed in a petri dish. After one or two days, the worm attached itself to the glass surface by secreting mucus, and formed new posterior end of the tube. At this time, the stolons of Proboscidactyla scattered around the newly formed tube end elongated onto the tube end and differentiated there only one or two polyps at their tip (Fig. 14). However, these polyps disappeared in three to five days. Generally the polyps differentiate only at the anterior end of the tube, but as in the above-mentioned case some polyps are able to differentiate on the tail end of the tube; this indicates that the worm has a capacity to induce polyp formation at both ends. On the other hand, when the polyps developed best the renovation of tube was carried out most actively by the worm.

\section{Summary and Conclusions}

\section{Cytaeis uchidae}

Colnoies of the hydrozoan, Cytaeis uchidae, are found associated with the gastropod, Niotha livescens. We have investigated the symbiotic relations between these species in terms of the differentiation of the polyp and medusa in the life cycle of $C$. uchidae. The colony of C. uchidae is found attached to the shell surface of $N$. livescens; the stolon runs along the reticulate grooves of the shell, and most polyps appear at the intersections of grooves. When a polyp was transplanted onto a substratum such as glass, vinyl chloride plate, shell of Mytilus, old empty shell or fresh empty shell of 
Niotha, it could survive only a limited time and did not develop to the colony of the normal pattern, although a subnormal survival occurred on the fresh empty shell. The medusa buds appeared from the end of July to August in both the field and the laboratory. During the off-season, numerous medusa buds could be differentiated under the following three conditions: from colonies formed on fresh empty shells, from colonies on broken pieces of the shell of living molluscs, and from expanded colonies transplanted on the glass bottom of a dish and kept separated by a gauze screen from a creeping gastropod that was placed in the same vessel. Medusa buds also appeared in colonies which were transplanted on the glass plate, the empty shell of Mytilus, and on the old empty shell of Niotha, but such colonies failed to survive more than a few days. The gastropod Niotha with associated colonies of Cytaeis appear on the sandy floor in June when the sea temperature rises to about $15^{\circ} \mathrm{C}$, and disappear in December when the temperature drops to $10^{\circ} \mathrm{C}$. The egg masses of $N$. livescens have been observed from the end of July to early August. Distinct medusa buds of C. uchidae were observed from the end of July to August or September. In other seasons, only occasionally medusa buds were observed in the material collected from the field and kept in the laboratory with sufficient food. The breeding season of $N$. livescens in summer coincides with the season of medusa formation of $C$. uchidae.

In the laboratory, specimens of Niotha were observed to secrete mucus in the petri

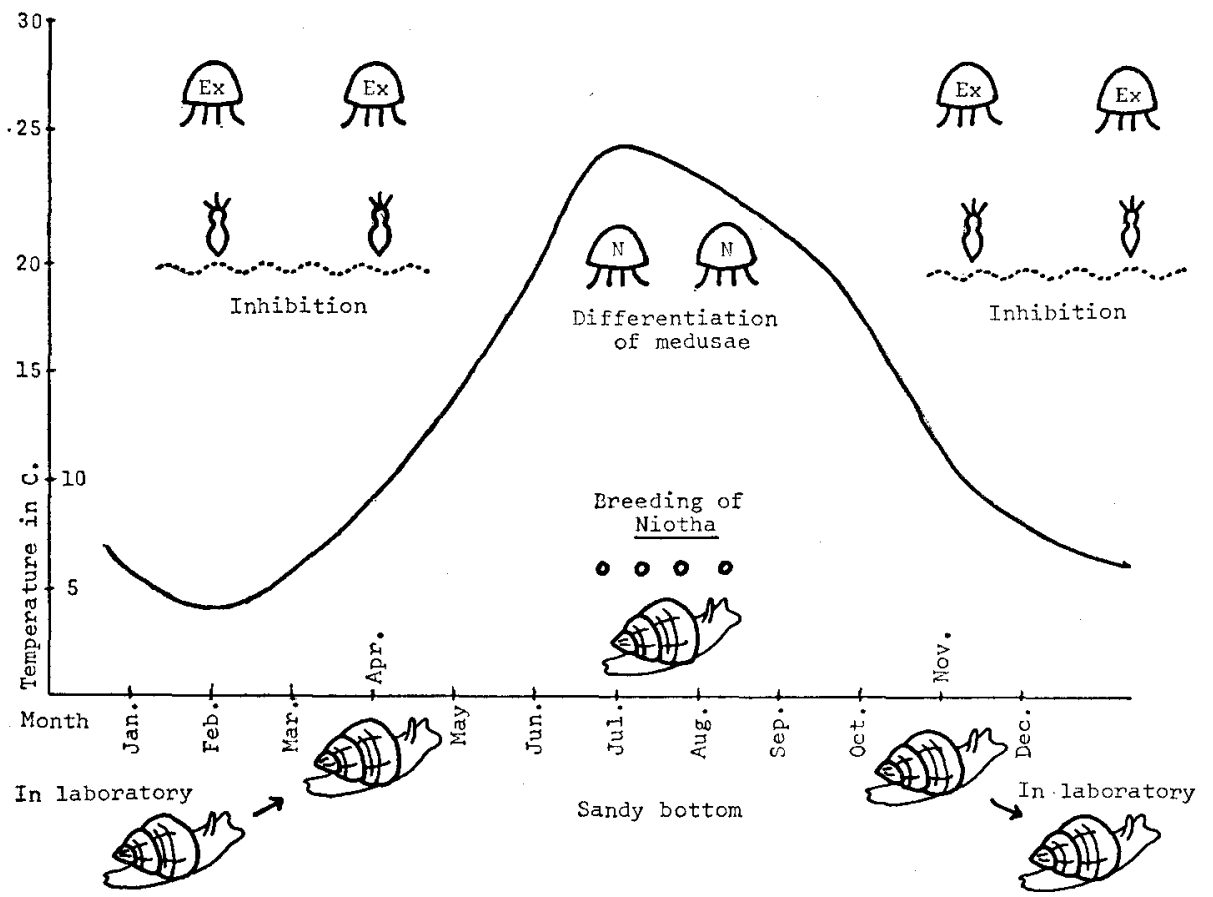

Fig. 15. Diagrammatic representation of the symbiotic relation between Cytaeis uchidae and its host Niotha livescens in terms of temperature. 
dish; this secretory activity was least conspicuous during their breeding season. From these observations, it is inferred that the medusa-forming condition is related to the mucus secretion of the snail, and to the time of maturation of Niotha, when the mucopolysaccharide usually secreted as mucus might be used to build up egg capsules. Whenever the animal body removed from the shell, numerous medusa appeared on the latter at $20^{\circ} \mathrm{C}$ at any time during the experiment. The same phenomenon happens during the breading season of Niotha. These observations can be interpreted as an indication that the mucus secreted by the gastropod in some way inhibits medusaformation of the hydrozoan (Fig. 15).

\section{Proboscidactyla sp.}

The hydrozoan Proboscidactyla sp. lives commensally on the tube of the polychaete, Pseudopotamilla occelata, its gonozooids arising directly from the stolon. The polyps differentiate only when the stolon maintains close contact with the worm body. When the stolon was placed in contact with isolated tentacles, collar, trunk or tail of the worm body, it was found that the polyp differentiation was induced by contact with only the trunk or tail pieces of the worm body, but never induced by tentacles or collar. The results of transplantation of stolons directly onto the worm body indicated that the differentiation of this hydrozoan is closely related to the tube-forming substance which is secreted by the worm, that the normal pattern of colony development of the hydrozoan depends on the presence of a living worm in the tube, and that the polychaete releases some substance which promotes the differentiation of the polyp. Moreover, polyp differentiation on the newly secreted tube of a juvenile polychaete required only half the time needed on an adult tube. The gastrozooids differentiated at the tube aperture survived for a long time, but those formed at the posterior end of the tube were smaller and survived only a short time. In some cases, the substance which is believed to promote the differentiation of the polyp may be unstable or occur in different quantities. It is clear that the normal pattern of the colony and the survival of the hydrozoan thus depend on the physiological condition of the polychaete. There is a close relation also between the life cycles of the polychaete and the hydrozoan. It is observed that when the polychaete carries out the active secretion of mucus for tube-building, the hydrozoan stolons have a better chance to differentiate into gastrozooids, maintaining the rhythm of active differentiation concerted with active secretion of the host polychaete.

It can be concluded that these two types of symbiotic relation have a basically similar mechanism. It is supposed that the differentiation of organs in these hydrozoans is controlled by the physiological activity of the host animal during its life cycle. We conclude from these experimental investigations on hydrozoan organogenesis and morphogenesis, that the differentiation of organs depends not only on the factors contained in the egg cell itself but also on various environmental factors during the life cycle. 


\section{LITERATURE CITED}

HiRaI, E. 1960. Some observations on differentiation of a colony of a hydrozoan, Proboscidactyla sp. Bull. Mar. Biol. Stat. Asamushi, 10: 27-30.

Hirai, E. and Y. Kakinuma, 1969. On the differentiation during the life cycle of a hydrozoan Proboscidactyla sp. Proc. Jap. Soc. Syst. Zool., No. 5, 1-2.

HiRAI, E. and Y. KaKinuma, 1970. A preliminary report on the differentiation of colony of a hydrozoan, Cytaeis uchidae. Bull. Mar. Biol. Stat. Asamushi, 14: 7-10.

HiRAi, E. and Y. KakinUma, 1971. On symbiotic relations between differentiation of a hydrozoan Cytaeis uchidae with a gastropod Niotha livescens. Bull. Mar. Biol. Stat. Asamushi, 14: 65-77.

KaKInUma, Y. 1971. On the differentiation of the organs during the life cycle Proboscidactyla sp. which is associated with the tube of Pseudopotamilla occelata. Bull. Mar. Biol. Stat. Asamushi, 14: 79-91.

\section{DISCUSSION}

Tomixama: Is the definite identification of that hydroid, Proboscidactyla sp., still pending?

Kakinuma: It has recently been identified, but tentatively, by Dr. UchiDa with Proboscidactyla flavicirrata. 